Check for updates

Cite this: RSC Adv., 2017, 7, 22797

Received 11th March 2017

Accepted 10th April 2017

DOI: $10.1039 / c 7 r a 02942 j$

rsc.li/rsc-advances

\section{Copper-catalyzed one-pot oxidative amidation between methylarenes and amines $\uparrow$}

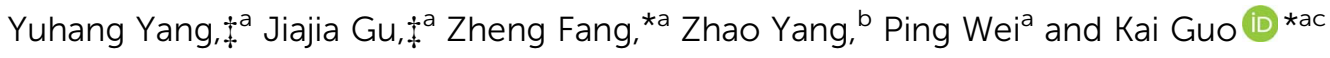 \\ A new method for the direct one-pot oxidative amidation between methylarenes and amines catalyzed by \\ copper has been developed. This method integrates methylarene oxidation and amide bond formation, \\ which are usually accomplished separately, into a single operation. In addition, the reaction provides \\ a relatively high yield and has a wide substrate scope. Moreover, the starting reagents are abundant and \\ available in a convenient way at a cheaper price.
}

\section{Introduction}

The formation of amide bond is one of the most important organic chemistry reactions because amide functional group has extensive applications in pharmaceutical compounds, natural products and polymers. ${ }^{1}$ The synthesis of amides is usually carried out through the reaction of carboxylic acids or carboxylic acid derivatives with amines in the presence of coupling reagents, ${ }^{2}$ which produce byproducts. ${ }^{3}$ Moreover, these approaches have several disadvantages, such as poor atom utilization, using hazardous reagents and generation of waste which causes environmental problems. To overcome these problems, alternative methods have been developed for amide syntheses, such as the Beckmann rearrangement, ${ }^{4}$ Staudinger reaction, ${ }^{5}$ Schmidt reaction ${ }^{6}$ and Ugi reaction. ${ }^{7}$ Other methods involving selective hydrolysis of nitrile, ${ }^{8}$ dehydrogenative amidation of alcohol, ${ }^{9}$ coupling of amine with $\alpha$-halonitroalkane promoted by iodonium, ${ }^{10}$ aminocarboxylation of aromatic halides, ${ }^{11}$ direct synthesis of amides from alcohols and nitroarenes or amines, ${ }^{12}$ transamidation of amines ${ }^{13}$ and oxidative amidation of aldehydes or alcohol ${ }^{14}$ have also been reported. Among these methods, oxidative amidation has received considerable attention in terms of green chemistry and economic factors and is highly desirable as it uses cheap, abundant and less hazardous starting materials.

Direct oxidative amidation has attracted much attention due to atom economy and environmentally benign issues. Toluene

${ }^{a}$ College of Biotechnology and Pharmaceutical Engineering, Nanjing Tech University, 30 Puzhu Rd S., Nanjing 211816, China. E-mail: guok@njtech.edu.cn; fzcpu@163. com; Fax: +86 255813 9935; Tel: +8625 58139926

${ }^{5}$ School of Engineering, China Pharmaceutical University, No. 639 Longmian Avenue, Nanjing 211198, China

'State Key Laboratory of Materials-Oriented Chemical Engineering, Nanjing Tech University, 30 Puzhu Rd S., Nanjing 211816, China

$\dagger$ Electronic supplementary information (ESI) available: General information and copies of ${ }^{1} \mathrm{H}$ and ${ }^{13} \mathrm{C}$ NMR spectra. See DOI: $10.1039 / \mathrm{c} 7 \mathrm{ra02942j}$

$\$$ These authors contributed to the work equally. and other methylarenes have also been used for oxidative amidation for the synthesis of aromatic amides. Mizuno and his co-workers reported the direct aerobic oxidative amidation of methylarenes using urea as the amine source in the presence of $\mathrm{MnO}_{2}$ catalyst (Scheme 1a). ${ }^{15}$ Even though the method was novel, the drawback was predictable. At $150{ }^{\circ} \mathrm{C}$, urea decomposes easily, thereby limiting the yield. $\mathrm{Wu}^{16}$ and $\operatorname{Sun}^{17}$ also used this strategy to synthesise amides employing $\mathrm{N}, \mathrm{N}$-dimethylformamide as the amine source in the presence of $\mathrm{ZnBr}_{2}$ catalyst (Scheme 1b). Recently, Wang et al. reported ironcatalyzed oxidative amidation of methylarenes (Scheme 1c). ${ }^{18}$ Through this method, methylarenes have performed well with primary amines; however, their yield was less when secondary amines were used. Singh ${ }^{19}$ and Sekar ${ }^{20}$ have reported the oxidative amidation of methylarenes using $N$-chloramine as the

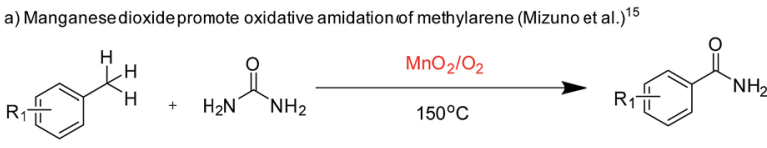

b) Zinc-calalyzed oxidative amidation of methylarene $\left(\mathrm{Wu},{ }^{16} \mathrm{Sun}^{17}\right)$

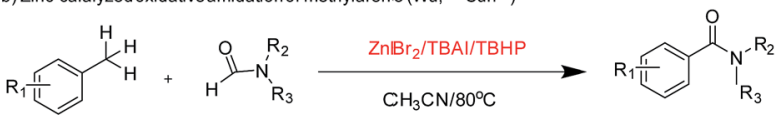

c) iron-calalyzed oxidative amidation of methylarene (Wang et al. $)^{18}$

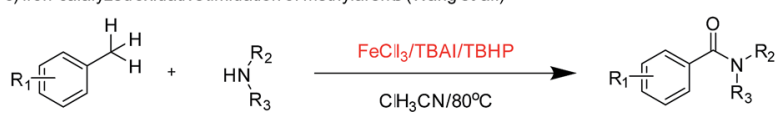

d) Manganese-or iron-calalyzedoxidative amidation of methylarene $\left(\operatorname{Singh}_{1}{ }^{19} \mathrm{Sekar}^{20}\right.$ )

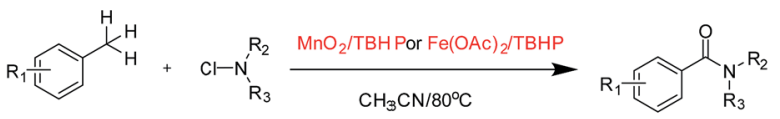

e) copper-catalyzed one-potoxidative amidation of methylarene(thiswork)

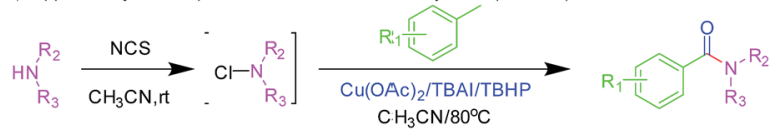

Scheme 1 Metal-catalyzed oxidative amidation of methylarenes and amines. 
amine source in the presence of $\mathrm{MnO}_{2}$ and $\mathrm{Fe}(\mathrm{OAc})_{2}$, respectively (Scheme 1d). However, methylarenes with electronwithdrawing group did not perform well with this method. Moreover, economic starting materials used in these studies would be more attractive for the chemical industry. However, rigorous reaction conditions for oxidative amidation of methylarenes and the limited substrate scope limits their applications. Herein, we report an efficient and green one-pot procedure for the direct oxidative amidation of methylarenes with $N$-chlorosuccinimide, which have been prepared from amines, catalyzed easily by accessible copper salts (Scheme 1e). The starting materials of the reaction are abundant, economical and easily accessible, and the method is green, efficient, simple and convenient. Moreover, the reaction has a wide range of substrate scope.

\section{Results and discussion}

Morpholine 1a (1.0 equiv.) and methylbenzene 2a (10 equiv.) were used as starting materials to synthesise benzoyl morpholine, and the reaction was regarded as template reaction. In the beginning, morpholine was treated with $\mathrm{N}$-chlorosuccinimide (NCS, 1.1 equiv.) at room temperature for $3 \mathrm{~h}$, and methylbenzene, $\mathrm{Cu}(\mathrm{OAc})_{2}(10 \% \mathrm{~mol})$ and TBHP (70\% wt in water, 8.0 equiv. $)$ were added into the reaction mixture under $80{ }^{\circ} \mathrm{C}$ to generate the amide product $3 \mathrm{a}$ with $48 \%$ yield (Table 1 , entry 1 ). The yield was not good, so the reaction condition should be optimized. Different parameters such as catalysts, oxidants, and solvents were examined. In the first step, different copper salts such as $\mathrm{Cu}(\mathrm{OAc})_{2}, \mathrm{CuSO}_{4} \cdot 5 \mathrm{H}_{2} \mathrm{O}$, and $\mathrm{CuCl}_{2}$ were used to test the reaction and $\mathrm{Cu}(\mathrm{OAc})_{2}$ has shown superior activity among all of the catalysts with $48 \%$ yield (Table 1, entries 1-8). Furthermore, different oxidants involving TBPB, $\mathrm{H}_{2} \mathrm{O}_{2}$ and $m$-CPBA were used to evaluate the reaction and the best results were obtained for TBHP (Table 1, entries 9-11). Moreover, the product was obtained only in trace amounts when $\mathrm{H}_{2} \mathrm{O}_{2}$ and $m$-CPBA were used as oxidants. There was no product observed in the absence of an oxidant (Table 1, entry 12). The amounts of reactants were studied (Table 1, entries 13-15), based on which, $20 \%$ mol of catalyst and 8.0 equiv. of oxidant were chosen as the best mole ratio. It was found that increasing the amount of oxidant unlimitedly and decreasing the amount of oxidant did not yield good results. Finally, some additives were used to improve the yield of the reaction (Table 1, entries 16-19). After using some additives, yield of the product improved significantly, and TBAI performed better than others. In addition, using TBAI as additive without catalyst decreased the yield to a great extent (Table 1 , entry 20 ).

After figuring out optimum reaction conditions, a large range of commercially available methylarenes was used to test the substrate scope for this reaction; the result has been displayed in Table 2. It was surprising to note that methylarenes with electron-donating groups, such as $\mathrm{CH}_{3}$ (Table 2, 3b-3d), $\mathrm{OCH}_{3}$ (Table 2, 3e), or electron-withdrawing groups, like $\mathrm{NO}_{2}$ (Table 2, 3f), Cl (Table 2, 3g), resulted in corresponding amide products with excellent yield. Moreover, it was notable that the reaction possessed excellent chemo-selectivity when amines reacted with $p$-xylene (Table $2,3 \mathbf{b}$ ), $m$-xylene (Table 2, 3c) and $o$ -
Table 1 Selected results for screening the optimum reaction conditions $^{a}$

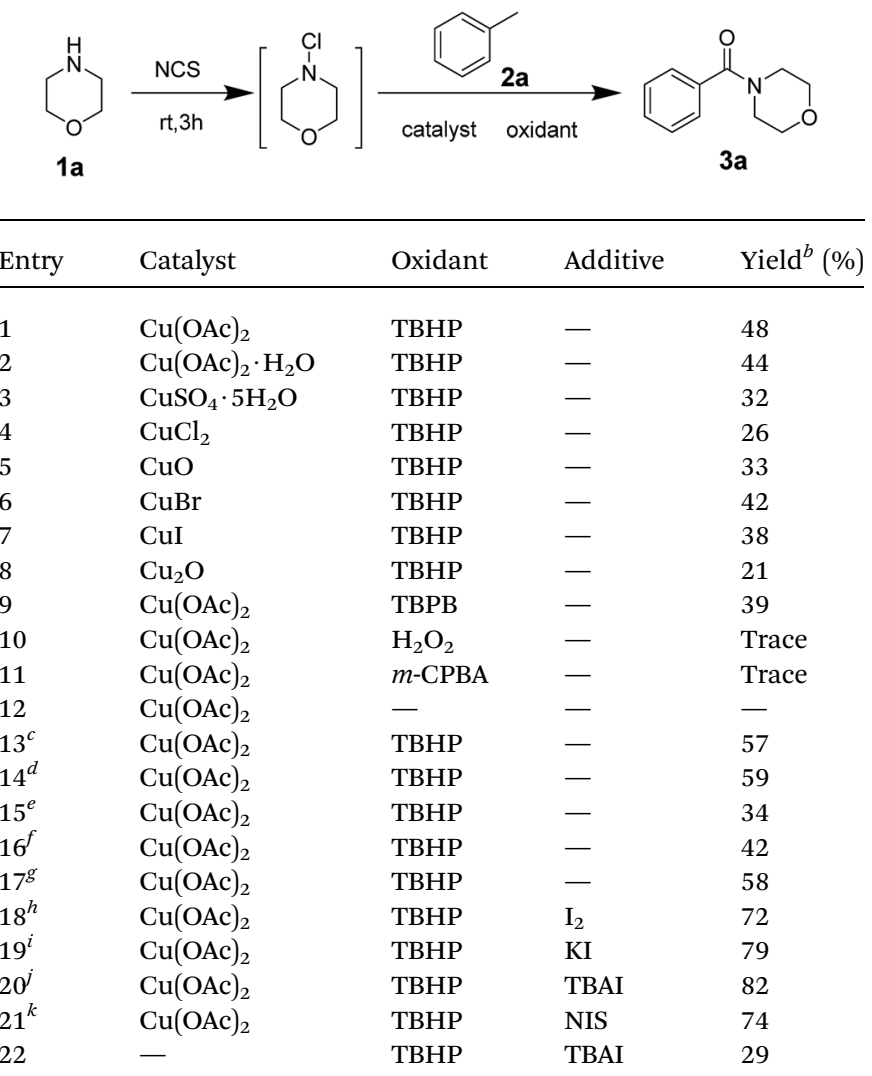

${ }^{a}$ Reaction conditions: morpholine $(1.5 \mathrm{mmol})$, NCS (1.65 mmol, 1.1 equiv.), in $10 \mathrm{~mL}$ acetonitrile, stirring at room temperature for $3 \mathrm{~h}$. To this reaction mixture, added toluene ( $15 \mathrm{mmol}, 10$ equiv.), catalyst (10 mol\%) and oxidant ( $12 \mathrm{mmol}, 8$ equiv.), stirring at $80{ }^{\circ} \mathrm{C}$ for $24 \mathrm{~h}$. ${ }^{b}$ Isolated yield. ${ }^{c}$ Reaction performed using $20 \mathrm{~mol} \%$ of $\mathrm{Cu}(\mathrm{OAc})_{2}$. ${ }^{d}$ Reaction performed using $50 \mathrm{~mol} \%$ of $\mathrm{Cu}(\mathrm{OAc})_{2} .{ }^{e}$ Reaction performed using $20 \mathrm{~mol} \%$ of $\mathrm{Cu}(\mathrm{OAc})_{2}$ and 3 equiv. of TBHP. ${ }^{f}$ Reaction performed using $20 \mathrm{~mol} \%$ of $\mathrm{Cu}(\mathrm{OAc})_{2}$ and 5 equiv. of TBHP. ${ }^{g}$ Reaction performed using $20 \mathrm{~mol} \%$ of $\mathrm{Cu}(\mathrm{OAc})_{2}$ and 10 equiv. of TBHP. ${ }^{h}$ Reaction performed using $20 \mathrm{~mol} \%$ of $\mathrm{Cu}(\mathrm{OAc})_{2}$ and $20 \mathrm{~mol} \%$ of $\mathrm{I}_{2} \cdot{ }^{i}$ Reaction performed using $20 \mathrm{~mol} \%$ of $\mathrm{Cu}(\mathrm{OAc})_{2}$ and $20 \mathrm{~mol} \%$ of KI. ${ }^{j}$ Reaction performed using $20 \mathrm{~mol} \%$ of $\mathrm{Cu}(\mathrm{OAc})_{2}$ and $20 \mathrm{~mol} \%$ of TBAI. ${ }^{k}$ Reaction performed using $20 \mathrm{~mol} \%$ of $\mathrm{Cu}(\mathrm{OAc})_{2}$ and $20 \mathrm{~mol} \%$ of NIS.

xylene (Table $2,3 \mathbf{d}$ ) to obtain mono-amide products. The reaction could even tolerate some heterocycles as substrates, such as thiophene (Table $2, \mathbf{3 h}$ ) or oxole (Table 2, 3i) and they performed well.

Moreover, commercially available amines were used to test the substrate scope of this reaction. The results of the test are shown in Table 3. The table shows that disubstituted amines, such as cyclic (Table $3, \mathbf{3 j}-\mathbf{3 l}$ ) and acyclic amines (Table $3, \mathbf{3 m}-$ 3n) played a great role in the reaction to obtain the corresponding amide products in good yields. Monosubstituted amines (Table 3, 3o-3r) have also shown excellent tolerance. On using amines with steric hindrance (Table 3, 3s-3t), results were good.

Aiming to exhibit the practical applications of the technology described above, we used copper-catalyzed one-pot oxidative 
Table 2 Scope of methylarenes ${ }^{a}$

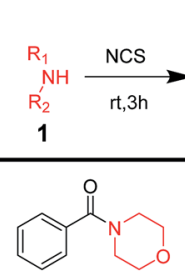

$3 a, 81 \%$<smiles>Cc1ccccc1C(=O)N1CCOCC1</smiles><smiles>COc1ccc(C(=O)N2CCOCC2)cc1</smiles><smiles>O=C(c1ccc(Cl)cc1)N1CCOCC1</smiles>

$3 g, 83 \%$

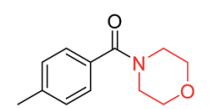

3b, $86 \%$
$\underbrace{R_{3} \frac{11}{R_{2}}}_{3}$

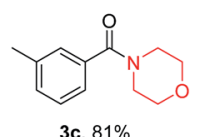

3c, $81 \%$
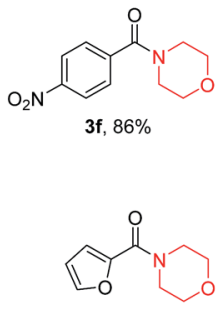

$3 \mathbf{i}, 82 \%$
${ }^{a}$ Reaction conditions: morpholine $(1.5 \mathrm{mmol})$, NCS $(1.65 \mathrm{mmol}, 1.1$ equiv.), in $10 \mathrm{~mL}$ acetonitrile, stirring at room temperature for $3 \mathrm{~h}$. To this reaction mixture, added methylarenes (15 mmol, 10 equiv.), catalyst $(20 \mathrm{~mol} \%)$, additive $(20 \mathrm{~mol} \%)$ and oxidant $(12 \mathrm{mmol}, 8$ equiv.), stirring at $80{ }^{\circ} \mathrm{C}$ for $24 \mathrm{~h}$.

Table 3 Scope of amines ${ }^{a}$

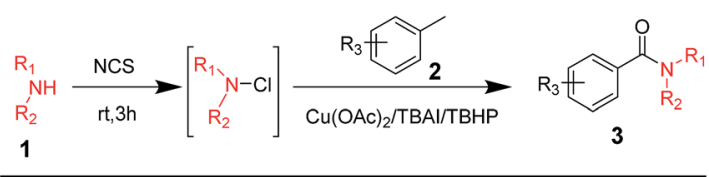

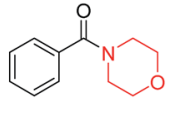

3a, $81 \%$<smiles>O=C(c1ccccc1)N1CCCC1</smiles>

$3 \mathrm{I}, 88 \%$<smiles>CCCCNC(=O)c1ccccc1</smiles>

3o, $79 \%$<smiles>O=C(NCc1ccccc1)c1ccccc1</smiles>

$3 r, 84 \%$<smiles>O=C(c1ccccc1)N1CCCCC1</smiles>

3j, $87 \%$<smiles>CCN(CC)C(=O)c1ccccc1</smiles>

$3 \mathrm{~m}, 66 \%$<smiles>O=C(Nc1ccccc1)c1ccccc1</smiles>

$3 p, 78 \%$<smiles>CC(C)(C)NC(=O)c1ccccc1</smiles>

3s, $64 \%$

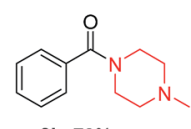

3k, $79 \%$
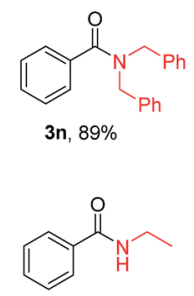

3q, $76 \%$

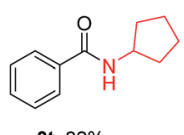

$3 \mathrm{t}, 82 \%$
${ }^{a}$ Reaction conditions: amines ( $\left.1.5 \mathrm{mmol}\right)$, NCS (1.65 mmol, 1.1 equiv.), in $10 \mathrm{~mL}$ acetonitrile, stirring at room temperature for $3 \mathrm{~h}$. To this reaction mixture, added toluene ( $15 \mathrm{mmol}, 10$ equiv.), catalyst ( 20 mol\%), additive ( $20 \mathrm{~mol} \%$ ) and oxidant (12 mmol, 8 equiv.), stirring at $80{ }^{\circ} \mathrm{C}$ for $24 \mathrm{~h}$. amidation as a key step to synthesise moclobemide, a type of monoamine oxidase inhibitor antidepressant. On beginning with commercially available methylarenes, parachlorotoluene, we were able to obtain the corresponding product with $69 \%$ yield (Scheme 2).

Based on previously reported studies, we considered a possible mechanism for this reaction and it is shown in Scheme 3. In the first step, TBAI was oxidized to $\mathrm{IO}^{-}\left({\mathrm{Or} \mathrm{IO}_{2}}^{-}\right)$ by TBHP, and TBHP transformed into $t$-BuOH. Then, $\mathrm{IO}^{-}$(or $\mathrm{IO}_{2}{ }^{-}$) acted as real oxidizing agent to oxidize toluene to benzyl alcohol and benzyl alcohol was further oxidized to benzyl aldehyde. Copper played an important role in the reaction. $\mathrm{Cu}(\mathrm{II})$ reacted with TBHP in such a way that TBHP transformed into tert-butylperoxy radical and $\mathrm{H}^{+}$. $\mathrm{Cu}(\mathrm{II})$ also transformed into $\mathrm{Cu}(\mathrm{I})$. Tert-butylperoxy radical captured a hydrogen from an aldehyde, thereby transforming the aldehyde into acyl group. With redox reaction, the protonated $N$-chloramine was transformed into amino radical, as reported by Minisci. ${ }^{21,22}$ In the last step, amino radical and the acyl groups were coupled to yield corresponding amide products. To verify the conjecture, acyl radical, generated from toluene under the abovementioned reaction conditions, was trapped with 2,2,6,6-tetramethylpiperidine-1-oxyl (TEMPO) resulting in the<smiles>Cc1ccc(Cl)cc1</smiles>

Scheme 2 Synthesis of moclobemide.

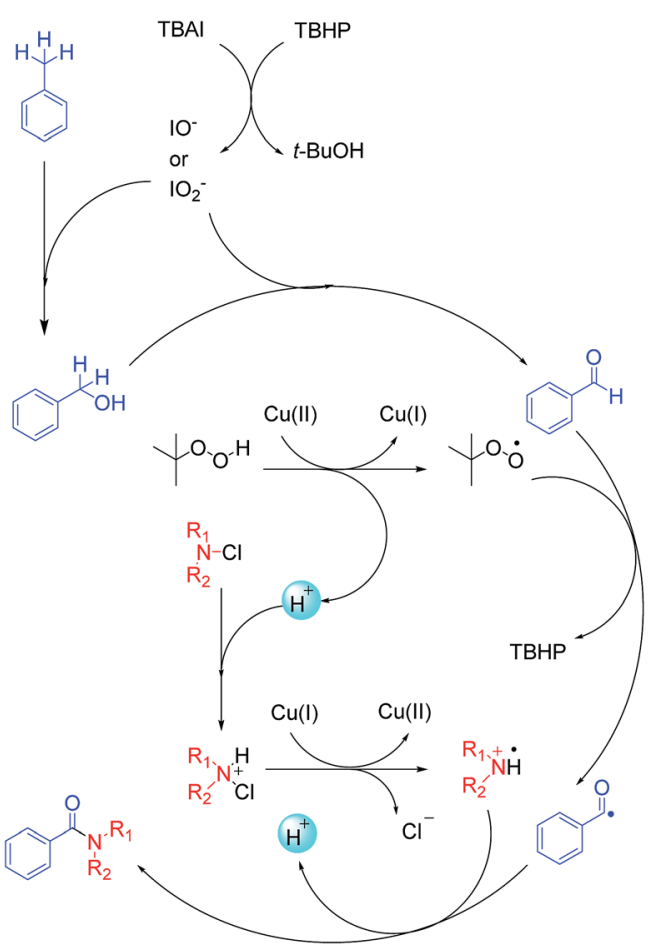

Scheme 3 Proposed mechanism for amide synthesis. 

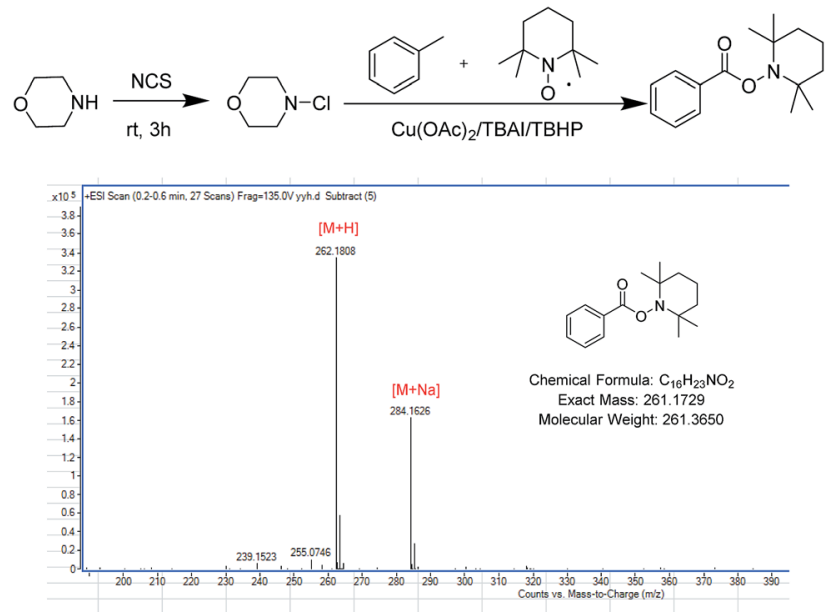

Scheme 4 Trapping of the acyl radical.

formation of TEMPO adduct, which was detected by HRMS (Scheme 4).

\section{Conclusions}

In summary, we developed an effective and environmentally friendly method for the synthesis of amides via coppercatalyzed one-pot direct oxidative amidation between methylarenes and amines. This method has combined methylarenes oxidation and amide bond formation into one procedure, which otherwise would follow two distinct steps. Using copper as a catalyst and TBHP as the sole oxidant proved to be economical too. What's more, the starting materials of the reaction are abundant, economical and easily accessible, and the reaction has a wide range of substrate scope.

\section{Acknowledgements}

This research has been supported by the National Natural Science Foundation of China (Grant No. 21522604, U1463201 and 21402240); the youth in Jiangsu Province Natural Science Fund (Grant No. BK20150031 and BY2014005-03); a Project Funded by the Priority Academic Program Development of Jiangsu Higher Education Institutions (PAPD).

\section{Notes and references}

1 J. M. Humphrey and A. R. Chamberlin, Chem. Rev., 1997, 97, 2243.

2 C. A. G. N. Montalbetti and V. Falque, Tetrahedron, 2005, 61, 10827.

3 Selected recent examples: (a) Y. J. Kang, H. A. Chung, J. J. Kim and Y. J. Yoon, Synthesis, 2002, 733; (b) I. Azumaya, T. Okamoto, F. Imabeppu and H. Takayanagi, Tetrahedron Lett., 2003, 59, 2325; (c) A. Teichert, K. Jantos, K. Harms and A. Studer, Org. Lett., 2004, 6, 3477; (d) D. M. Shendage, R. Froehlich and G. Haufe, Org. Lett., 2004, 6, 3675; (e) D. A. Black and B. A. Arndtsen, Org. Lett.,
2006, 8, 1991; (f) A. R. Katritzky, C. Cai and S. K. Singh, J. Org. Chem., 2006, 71, 3375; $(g)$ S. D. Roughley and A. M. Jordan, J. Med. Chem., 2011, 54, 3451.

4 (a) E. Beckmann, Ber. Dtsch. Chem. Ges., 1886, 89, 988; (b) N. A. Owston, A. J. Parker and J. M. J. Williams, Org. Lett., 2007, 9, 3599.

5 (a) Y. G. Gololobov and L. F. Kasukhin, Tetrahedron, 1992, 48, 1353; (b) E. Saxon and C. R. Bertozzi, Science, 2000, 287, 2007; (c) F. Damkaci and P. DeShong, J. Am. Chem. Soc., 2003, 125, 4408.

6 (a) T. Ribelin, C. E. Katz, D. G. English, S. Smith, A. K. Manukyan, V. W. Day, B. Neusenswander, J. L. Poutsma and J. Aube, Angew. Chem., 2008, 120, 6329; Angew. Chem., Int. Ed., 2008, 47, 6233; (b) S. Lang and J. A. Murphy, Chem. Soc. Rev., 2006, 35, 146.

7 I. Ugi, Angew. Chem., 1962, 74, 9; Angew. Chem., Int. Ed. Engl., 1962, 1, 8.

8 (a) P. M. Bendale and B. M. Khadilkar, Synth. Commun., 2000, 30, 1715; (b) Z. Gordi and H. Eshghi, J. Korean Chem. Soc., 2011, 55, 716.

9 (a) S. Cho, E. Yoo, I. Bae and S. Chang, J. Am. Chem. Soc., 2005, 127, 16046; (b) Z. W. Chen, H. F. Jiang, X. Y. Pan and Z. J. He, Tetrahedron, 2011, 67, 5920.

10 B. Shen, D. M. Makley and J. N. Johnston, Nature, 2010, 465, 1027.

11 J. R. Martinelli, T. P. Clark, D. A. Watson, R. H. Munday and S. L. Buchwald, Angew. Chem., Int. Ed., 2007, 46, 8460.

12 C. Chen and S. H. Hong, Org. Biomol. Chem., 2011, 9, 20.

13 (a) M. Tamura, T. Tonomura, K. i. Shimizu and A. Satsuma, Green Chem., 2012, 14, 717; (b) T. A. Dineen, M. A. Zajac and A. G. Myers, J. Am. Chem. Soc., 2006, 128, 16406; (c) M. Zhang, S. Imm, S. Baehn, L. Neubert, H. Neumann and M. Beller, Angew. Chem., Int. Ed., 2012, 51, 3905.

14 (a) S. D. Sarkar and A. Studer, Org. Lett., 2010, 12, 1992; (b) S. C. Ghosh, J. S. Y. Ngiam, C. L. L. Chai, A. M. Seayad, D. T. Tuan and A. Chen, Adv. Synth. Catal., 2012, 354, 1407; (c) C. G. Subhash, S. Y. N. Joyce, A. M. Seayad, T. T. Dang, C. L. L. Chai and A. Q. Chen, J. Org. Chem., 2012, 77, 8007; (d) C. Roberta, P. Andrea, G. Giampaolo and L. D. Luca, Org. Lett., 2012, 14, 5014; (e) J. J. Gu, Z. Fang, C. K. Liu, X. Li, P. Wei and K. Guo, RSC Adv., 2016, 6, 72121; (f) J. J. Gu, Z. Fang, Y. H. Yang, Z. Yang, X. Li, L. Wan, P. Wei and K. Guo, $R S C A d v .$, 2016, 6, 89413; (g) J. J. Gu, Z. Fang, C. K. Liu, Z. Yang, X. Li, P. Wei and K. Guo, RSC Adv., 2015, 5, 95014; (h) K. Yamaguchi, H. Kobayashi, T. Oishi and N. Mizuno, Angew. Chem., Int. Ed., 2012, 51, 544; (i) K. Xu, Y. Hu, S. Z. Zha and Z. Wang, Chem.-Eur. J., 2012, 18, 9793.

15 Y. Wang, K. Yamaguchi and N. Mizuno, Angew. Chem., Int. Ed., 2012, 51, 7250.

16 J. B. Feng, D. Wei, J. L. Gong, X. Qi and X. F. Wu, Tetrahedron Lett., 2014, 55, 5082.

17 B. Du and P. Sun, Sci. China: Chem., 2014, 57, 1176.

18 T. Wang, L. Yuan, Z. G. Zhao, A. L. Shao, M. Gao, Y. F. Huang, F. Xiong, H. L. Zhang and J. F. Zhao, Green Chem., 2015, 17, 2741. 
19 R. Vanjari, T. Guntreddi and K. N. Singh, Org. Lett., 2013, 15, 21 F. Minisci, F. Fontana, S. Araneo, F. Recupero, S. Ban and 4908.

S. Quici, J. Am. Chem. Soc., 1995, 117, 226.

20 S. S. Kotha, S. Badigenchala and G. Sekar, Adv. Synth. Catal., 22 F. Minisci, Synthesis, 1973, 1. 2015, 357, 1437. 